\title{
CORRIGENDUM
}

\section{Synergy between expression of fusogenic membrane proteins, chemotherapy and facultative virotherapy in colorectal cancer}

\author{
D Hoffmann, JM Bangen, W Bayer and O Wildner
}

Gene Therapy (2008) 15, 65; doi:10.1038/sj.gt.3303083

Correction to: Gene Therapy (2006) 13, 1534-1544. doi:10.1038/sj.gt.3302806

Since the publication of the above article, the authors have identified an error in Figure $3 a$ of the above paper.
The correct figure is shown below. The conclusions drawn from the figure are not affected by this unintentional mistake. The authors would like to apologize for this mistake.
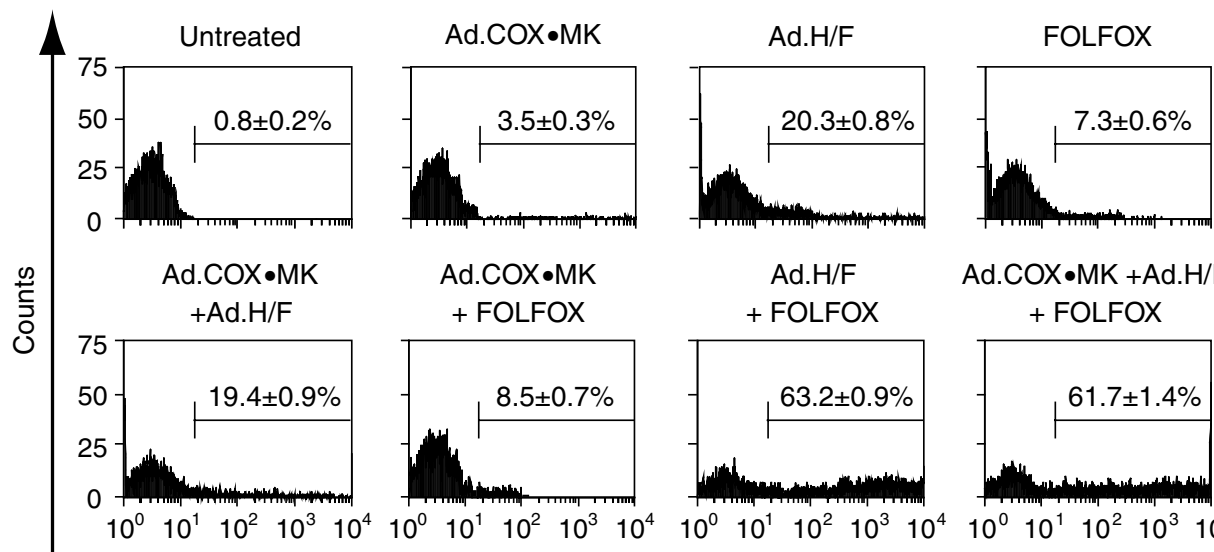

Ad.COX $\bullet M K+A d . H / F$ + FOLFOX

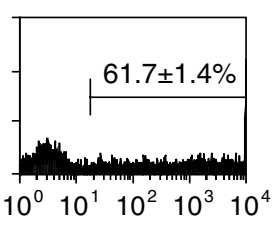

Annexin V (FL1-H) 